\title{
Review Article \\ Driving into the Sunset: Supporting Cognitive Functioning in Older Drivers
}

\author{
Mark S. Young ${ }^{1}$ and David Bunce ${ }^{2,3}$ \\ ${ }^{1}$ Ergonomics Research Group, School of Engineering and Design, Brunel University, Uxbridge UB8 3PH, UK \\ ${ }^{2}$ Department of Psychology, Centre for Cognition and Neuroimaging, Brunel University, Uxbridge UB8 3PH, UK \\ ${ }^{3}$ Centre for Mental Health Research, Australian National University, Canberra, ACT 0200, Australia
}

Correspondence should be addressed to Mark S. Young, m.young@brunel.ac.uk

Received 14 December 2010; Revised 17 March 2011; Accepted 31 March 2011

Academic Editor: Lynda Anderson

Copyright (C) 2011 M. S. Young and D. Bunce. This is an open access article distributed under the Creative Commons Attribution License, which permits unrestricted use, distribution, and reproduction in any medium, provided the original work is properly cited.

The rise in the aging driver population presents society with a significant challengeroads. On the one hand, older drivers pose a higher risk of an at-fault accident on a mile-for-mile basis; on the other hand, independent mobility is a significant marker of quality of life in aging. In this paper, we review the respective literatures on cognitive neuropsychology and ergonomics to suggest a previously unexplored synergy between these two fields. We argue that this conceptual overlap can form the basis for future solutions to what has been called "the older driver problem." Such solutions could be found in a range of emerging driver assistance technologies offered by vehicle manufacturers, which have the potential to compensate for the specific cognitive decrements associated with aging that are related to driving.

\section{Introduction}

There is no doubt that our aging population presents society with a number of economic and public health challenges. One of these challenges is transport, more specifically, personal transport. Recent figures released by the UK Automobile Association predict that, in 20 years, $90 \%$ of men and $80 \%$ of women aged over 70 years will hold a driving licence. Contrast this with the situation today, where three-quarters of men and only $31 \%$ of women in that age group drive. In absolute terms, the number of drivers over 70 is set to double in 20 years [1] and hit 10 million by 2050. It is also widely agreed that, per vehicle mile travelled, older drivers are at a higher risk of a fatal crash (e.g., [2]). These figures raise concerns for road safety - with more older drivers driving more miles, and, for more years [3], there could be a profound impact on absolute numbers of road casualties in the future.

But in an enlightened society, road safety is only one half of the older driver "problem," as Evans [4] puts it; we have a responsibility to meet the mobility needs of a growing population of older adults [5]. Well-being in older people depends to a large extent on their ability to successfully engage with various practical and recreational activities in daily life [6]. In turn, many of these activities are dependent on being able to drive. Driving thus enables older adults to "keep on living" independently and maintain their quality of life $[7,8]$. Evans' $[4]$ point is that the older driver "problem" is actually a problem for society-not just a case of getting them off the roads. Indeed, many older people actually restrict their driving boundaries to conditions where they feel safe and comfortable [9-11], further compounding the problem.

A solution is required which not only supports older drivers but also balances their requirements with road safety targets to continue reducing the number of killed and seriously injured on the roads. Adopting a more user-centred approach, such an alternative would be to compensate for the cognitive limitations of older drivers by making "...changes to the driving environment to make driving safer for the older person, both inside the car in terms of design factors, and perhaps advanced driving information systems, but also outside in terms of traffic system design" [12, page 5]. Both academic (e.g., $[10,13])$ and policy reports (e.g., $[1,3,7,12]$ 
have suggested that such a solution should exploit vehicle design and safety technology innovations inside the car, underpinned by a sound understanding of the older driver's cognitive abilities and information requirements. "There is a very clear need for such research addressing appropriate technology to aid safe car driving behaviour amongst the older driver population" [10].

A major objective of this paper is to consider the literature from several perspectives to understand and propose solutions for the older driver "problem." Research from cognitive neuropsychology and driving ergonomics is examined, and important synergies and parallels between the two fields are identified as a basis for taking this work forward. Specifically, we suggest that a promising basis for future research stems from work into cognitive inconsistency in neuropsychology and interest in driving performance consistency in ergonomics. Firstly, though, we look at road safety statistics to determine the extent of the problem.

\section{Older Drivers and Road Accidents}

Although there is some debate over the prevalence of older drivers in road accident statistics, it is widely agreed that, when controlling for exposure, drivers over 70 are at increased risk of an at-fault accident-with the data being comparable to those for the under-25 age group (e.g., $[2,4,9$, $11,13-15])$. Casualty rates per mile driven increase with age after 70-75 years [16], and the risk increases exponentially for drivers in their 80 s $[4,11,14]$. Whilst physical frailty is undoubtedly a factor in these statistics, the evidence for an association between age and crash risk is growing; any remaining doubt is probably more due to the smaller population of older drivers and "self-regulation" of their driving behaviours (cf. [4]).

Indeed, we currently rely on self-regulation to control the risk-expecting older drivers to declare for themselves when they are unfit to drive. But the evidence suggests this does not always work-many drivers are not aware of (or do not recognise) their own limitations $[9,11]$, and they either do not cease driving early enough or conversely cease driving too soon [17]. "Because of (a) lack of information, feedback, and insight, elderly drivers are not, I believe, in a good position to determine for themselves when they should reduce or cease driving" [9, page 171]. Moreover, as the older driving population grows and becomes more mobile, it is anticipated that mileages will increase, as will the need to face more challenging traffic conditions [12].

We have already said that, per mile driven, older drivers are almost at a similar risk of a crash as young drivers. When the types of accidents are analysed, though, it is clear that older drivers differ from younger groups in that their accidents are less about taking risks, but more about errors of perception or judgement $[2,4,11,14]$. Rather than singlevehicle accidents involving speed, alcohol, or fatigue, older drivers have multiple-vehicle accidents at junctions involving giving way, or when turning or changing lanes. This tends to be due to deficits in "bottom-up" visual and cognitive processing, as opposed to "top-down" failures of experience or expertise [13]. Verhaegen [18] argues that this decrement in performance is consistent with the notion that cognitive abilities decline with age.

\section{Cognitive Factors in Driving Performance}

There is a wide body of scientific evidence to suggest that age-related declines in cognitive functions such as attention and decision making can be a source of increased crash risk on the roads (e.g., [18-20]). Aging leads to declines in many perceptual and cognitive functions related to driving, with visual, spatial, and attentional abilities all having been shown as potential sources of increased risk. Whilst the reduction in driver capabilities with age can be offset with experience $[4,21]$, as age increases beyond 65 years, fitness to drive (in terms of sensory, perceptual, and cognitive abilities) becomes the most important factor in driving competence [22]. It has been shown that older drivers (over 60) are slower, less accurate, and less coordinated in their responses [23]. Tsimhoni and Green [24] used visual occlusion to demonstrate that drivers over the age of 55 experience more demand during driving on curved road sections, while Brouwer et al. [19] found that drivers in their mid-60s were less able to divide attention and integrate their responses in a dual-task scenario. In terms of driving tasks, negotiating junctions and merging traffic are both known to cause particular difficulties.

Undoubtedly, many of the problems that older drivers face are in part due to declining visual capabilities with age, affecting visual search at junctions (e.g., [14, 25]). Typically, it is the ambient or peripheral visual field which degrades $[25,26]$, leading some researchers to argue for a "useful field-of-view" (UFOV) test to predict driving performance (e.g., [27]). One such test has demonstrated sensitivity to crash risk in older drivers [28] and shows promise as a screening instrument [27]. However, there is a significant body of evidence to show that visual acuity and the UFOV test do not predict all aspects of driving performance (e.g., $[28,29])$ and that central cognitive processing plays a key role alongside visual perception and decision making $[5,11,13$, $18]$.

Attention and executive function have both been implicated as predictors of driving performance [19, 28, 30], with older drivers being more susceptible to errors under conditions of high mental workload $[9,11]$. Such cognitive declines are an inevitable part of the aging process: "Agerelated decline in cognitive functions such as attention, anticipation, executive functioning and information processing means that older drivers tend to have difficulty in dealing with complex traffic situations and reduced capacity to respond quickly and flexibly to changing traffic situations" [3, page 45]. Adrian [30] drew upon an established model of executive functioning and a standardised battery of tests to show that this is probably due to older drivers having difficulties with distraction and focusing their attention.

The idea of investigating independent cognitive measures in relation to driving performance in older adults is not 
new, and although meta-analyses and reviews (e.g., [31, 32]) suggest that tests of visuospatial skills may have some promise, the majority of studies have produced mixed findings. Efforts to develop metrics of individual cognitive abilities as correlates of driving performance have met with varying degrees of success [11,31-33]. In particular, low to moderate correlations between cognitive measures and driving performance make it difficult to distinguish between those who are fit and unfit to drive, and those studies reporting high correlations have not been replicated. Reasons for these discrepant findings include the often small sample sizes, the wide variety of cognitive measures that have been assessed, and the different approaches to assessment of driving performance, their varying realism and their rigour. Thus there remains a "desperate" need for evidence-based guidelines and tests for front-line application [33].

\section{New Perspectives from Cognitive Neuropsychology and Ergonomics}

The most apparent consequence of cognitive decline with aging is reaction time, which is slower for older drivers $[4,9]$. Recently though, there has been considerable interest in the cognitive aging field for investigating intraindividual variability, or inconsistency, of reaction time (RT) performance. Such measures index moment-to-moment fluctuations in performance over successive trials of a given cognitive task and are thought to reflect neurobiological integrity (e.g., $[34,35])$. Consistent with this view, increased variability is associated with older age (e.g., $[36,37]$ ) and a range of neurological conditions including dementia [38] and is a sensitive metric of cognitive function in older adults (e.g., [34]). Importantly, measures of RT inconsistency are sensitive to relatively subtle effects when standard measures of accuracy and mean RT from the same tasks are not. For example, recent work $[39,40]$ found that the cognitive effects of increasing age and mild mental health disorders (anxiety and depression) were detected by measures of inconsistency, but not by measures of accuracy and mean RT. Data supporting the view that inconsistency is associated with neurobiological integrity were produced in a recent neuroimaging study [41] of apparently healthy 60- to 64year olds; RT inconsistency was related to the degree of white matter lesioning in the frontal cortex, whereas mean RT was not. This work has now been extended to demonstrate the same association in 44- to 48-year olds [42]. These studies clearly suggest that measures of RT inconsistency are sensitive not only to subtle effects in aging contexts but also to neurobiological integrity.

Meanwhile, ergonomics research into driving performance has developed along parallel lines, with an important and distinguishing aspect of performance being consistency in driving-both in terms of perceptual judgements [9] and vehicle control. Bloomfield and Carroll [43] pioneered measures of lateral and longitudinal inconsistency in a driving simulator, arguing that these variables were more appropriate metrics of driving performance than traditional measures of mean or standard deviation. Their measures have since been successfully applied in several of our studies in the Brunel University Driving Simulator (e.g., $[44,45])$ and clearly distinguish good from poor drivers [46], in line with best practice for safe driving which suggests that smoothness and consistency is key [47]. Whilst the ecological validity of simulator studies may be called into question, many modern simulators offer realistic and immersive representations of driving and provide a safe, replicable, and controllable environment for studies of this nature. Moreover, with relevance to the present discussion, the higher-level cognitive and performance markers associated with driving are directly testable in a simulator.

Given the conceptual overlap with measures of cognitive inconsistency above, these studies together suggest that measures of RT inconsistency have huge potential in the present context. It is striking, though, that to date no work has drawn these two lines of research together. We believe the parallels between consistency-based metrics of driving and PC-administered measures of cognitive performance provide a promising and innovative basis from which to develop metrics and models that can help us better understand the cognitive limitations of older drivers. Pilot studies in our laboratory indicate that older adults (in comparison to a younger group) exhibit higher inconsistency on a neuropsychological test battery as well as higher inconsistency on driving performance metrics in a simulator.

Future research is planned to investigate and validate these associations in more detail. In terms of their application, there are two options. The first is in response to calls for compulsory screening tests for older drivers: “... instead of asking whether and why older people have more accidents ... perhaps we should be asking which older drivers are more likely to have accidents" [12, page 45]. Previous assumptions about identifying a threshold age beyond which deterioration in cognitive functioning presents an unacceptable risk to driving have met with limited success, as individual differences make crude age-related cut-offs inappropriate $[1,4,7$, 11, 48]. A more detailed instrument, tailored to individual differences, could be of use for drivers themselves in selfdiagnosis, as well as by General Practitioners (GPs) as part of a wider battery assessing medical-psychological fitness to drive. Such cognitive testing could be in addition to existing practices for GP assessments, which include visual acuity, general health, and medications. Anecdotal evidence suggests that GPs are currently uncomfortable with screening patients for driving ability, since they are not experts in driving standards. A cognitive testing instrument, as suggested here and elsewhere (e.g., [22]), used in conjunction with standard medical assessment may help reassurance and reliability in these processes.

However, such screening remains contentious and does not accord with the spirit of solving the older driver problem-maintaining safety and mobility. The aim is to prolong independence, rather than try to remove older drivers from their cars. In that respect, we can turn to usercentred design and a raft of technological support systems that are becoming available in cars. 


\section{Vehicle Technology and Design to Support Older Drivers}

Numerous in-car technologies are coming on stream now that could support the cognitive functioning of older drivers (cf. $[3,10])$, such as blind spot warning systems, lane keeping assistance, adaptive cruise control, speed limit displays, and collision mitigation braking systems. Nevertheless, such systems are very much a result of technology "push" rather than user "pull"; what is needed is a balanced, user-centred assessment of these technologies.

The user-centred approach would argue that the cognitive limitations of older drivers may be compensated for by technological interventions which support the older driver in maintaining their independence and mobility. For instance, vision enhancement systems could assist visual impairment associated with night-time driving; similarly a head-up display (HUD) could relieve the visual accommodation problems of eyesight in old age. Collision avoidance systems could help with speed and gap judgements at junctions, while adaptive cruise control or active steering could help reduce the demands of challenging driving situations.

Earlier research in this area with younger drivers (i.e., under 55 years) has shown that these systems can reduce driver workload and bring some improvements to driving performance [44, 49-51]. Extrapolating such results to older drivers may not be straightforward, though; Waller [52] notes that the extent to which "... new technology could assist (older drivers) is not known. Nevertheless, if new technology is designed, taking into account the abilities and limitations of older users, it holds promise of extending the self-sufficiency of many elderly drivers" (page 24).

Lees and Lee [13] suggest that emerging vehicle technologies can be exploited to enhance the safety of older and younger drivers, by tailoring such systems to support bottom-up or top-down processing, respectively. Previous research on younger drivers supports this, indicating that advanced driver assistance systems (ADASs) can bring some improvements to driving performance $[45,49]$, while European projects such as PReVENT and EDDIT [53] have explored the potential for extending these findings for the specific needs of older drivers. Moreover, a recent UK project explored this very issue and reported that most new in-car technologies have so far ignored older drivers' needs [10]. Using participatory methods, older drivers identified systems that enhanced feedback as having potential to assist their driving. However, this approach could exacerbate problems of high mental workload with older drivers $[9,11]$.

In particular, the diminished capacities of older drivers could render them more susceptible to overload with poorly designed assistance (cf. [20,48]). Earlier work in the DRIVAGE project (e.g., [48]) set out to evaluate the driving abilities of older people and to examine the potential benefits and distractions of providing additional information to the driver. More recently, a government report [3] noted that in-vehicle systems could specifically help older drivers but also cautioned that interface design and divided attention limitations might cancel out such benefits. That said, Horberry et al. [54] found that older drivers were no more susceptible to distraction from in-car systems than younger drivers. Moreover, the technological limitations of earlier systems are rapidly being overcome, and new advances in multisensory displays offer enhanced feedback whilst avoiding distraction or overload for the older driver (cf. [55]).

Results from the DRIVAGE project [56] and elsewhere [57] suggest that technological assistance inside the car is only of benefit if designed from a user-centred perspective. More recent research has indicated the potential of developing high technology vehicular interfaces using participatory methods specifically to meet the needs of older drivers [57]. This research also highlighted that the theoretical opportunity for a technology to assist with specific limitations of older drivers could not always be accessed by the older driver group for a variety of reasons, including poor user interface design and technology immaturity [57]. More research is clearly necessary to develop technologies and interfaces which not only support older drivers but are also acceptable and accessible to the population of older drivers.

Thus we see that, on the one hand we have technological options, and on the other we have the needs and wants of older drivers (e.g., $[10,57])$. But so far we do not have a complete user-centred solution based not only on the desires of older drivers but also their objective information processing requirements. To finish, we bring together the themes covered in this paper to argue for a new stream of research addressing the older driver problem.

\section{Summary and Conclusions}

We have seen that, mile for mile, older drivers are at greater risk of a collision than those between the ages of 25 and 55. One reason for this increase in risk is the decline in cognitive abilities with aging, particularly executive function. But individual differences in the aging process, as well as societal acceptability, make it unreasonable to set an agerelated threshold for dictating when older drivers should give up their licence. Indeed, the user-centred solution searches for technologies to support older drivers in maintaining safety and mobility.

There are many technologies offered by vehicle manufacturers now, with more arriving in the near future, that could fulfil this purpose. However, few-if any-of these have been designed specifically for older drivers, and so their benefits may be limited. Participatory research has identified the needs and wants of older drivers when it comes to technology; it is our contention that this is only half of the story, as systems should be specifically designed to compensate for the cognitive decrements associated with aging.

Many researchers have tried to identify those decrements with respect to driving performance, with varying degrees of success. We believe that we have discovered a promising avenue of investigation in the conceptual overlap between measures of intraindividual variability from the cognitive neuropsychology of aging and metrics of driving inconsistency from ergonomics. Future research is planned to explore these overlaps in rigorous empirical studies and to use the 
output as a basis for specifying technological support systems for older drivers. If we can identify systems to improve consistency in driving, we can go some way to solving the older driver problem.

\section{Acknowledgment}

D. Bunce received support from the Leverhulme Trust, UK.

\section{References}

[1] IAM, Older Drivers-Safe or Unsafe? Institute of Advanced Motorists, London, UK, 2010.

[2] G. McGwin and D. B. Brown, "Characteristics of traffic crashes among young, middle-aged, and older drivers," Accident Analysis \& Prevention, vol. 31, no. 3, pp. 181-198, 1999.

[3] PACTS, Beyond 2010-a holistic approach to road safety in Great Britain, Parliamentary Advisory Council for Transport Safety, London, UK, 2007.

[4] L. Evans, Traffic Safety, Science Serving Society, Bloomfield Hills, Mich, USA, 2004.

[5] K. Ball, "Attentional problems and older drivers," Alzheimer Disease and Associated Disorders, vol. 11, no. 1, pp. 42-47, 1997.

[6] V. H. Menec and J. G. Chipperfield, "Remaining active in later life: the role of locus of control in seniors' leisure activity participation, health, and life satisfaction," Journal of Aging and Health, vol. 9, no. 1, pp. 105-125, 1997.

[7] E. Box, J. Gandolfi, and K. Mitchell, Maintaining Safe Mobility for the Ageing Population: The Role of the Private Car, RAC Foundation, London, UK, 2010.

[8] M. Gilhooly, K. Hamilton, M. O’Neil, J. Gow, N. Webster, and F. Pike, "Transport and ageing: extending quality of life for older people via public and private transport," End of award report on ESRC Award Reference Number L480 254025.

[9] J. A. Groeger, Understanding Driving: Applying Cognitive Psychology to a Complex Everyday Task, Psychology Press, Hove, UK, 2000.

[10] H. Haddad and C. Musselwhite, "Prolonging Safe Driving Through Technology," SPARC Research Briefing Sheet 024, Centre for Transport \& Society, University of the West of England, Bristol, UK, 2007.

[11] G. Hole, The Psychology of Driving, LEA, Mahwah, NJ, USA, 2007.

[12] DfT, “Older drivers: a literature review," Road Safety Research Report 25, Department for Transport, London, UK, November 2001, http://webarchive.nationalarchives.gov.uk/+ /http: //www.dft.gov.uk/pgr/roadsafety/research/rsrr/theme3 /olderdriversaliteraturerevie4770.

[13] M. N. Lees and J. D. Lee, "Enhancing safety by augmenting information acquisition in the driving environment," in Human Factors of Visual and Cognitive Performance in Driving, C. Castro, Ed., pp. 167-186, CRC Press, Boca Raton, Fla, USA, 2009.

[14] DfT, "Collisions involving older drivers: an in-depth study," Road Safety Research Report 109, Department for Transport, London, UK, 2009.

[15] G. McGwin, C. Owsley, and K. Ball, "Identifying crash involvement among older drivers: agreement between selfreport and state records," Accident Analysis \& Prevention, vol. 30, no. 6, pp. 781-791, 1998.
[16] J. Eberhard, "Older drivers' "high per-mile crash involvement": the implications for licensing authorities," Traffic Injury Prevention, vol. 9, no. 4, pp. 284-290, 2008.

[17] C. Berry, Can Older Drivers Be Nudged? How the Public and Private Sectors Can Influence Older Drivers' Self-Regulation, RAC Foundation, London, UK, 2011.

[18] P. Verhaegen, "Liability of older drivers in collisions," Ergonomics, vol. 38, no. 3, pp. 499-507, 1995.

[19] W. H. Brouwer, W. Waterink, P. C. Van Wolffelaar, and T. Rothengatter, "Divided attention in experienced young and older drivers: lane tracking and visual analysis in a dynamic driving simulator," Human Factors, vol. 33, no. 5, pp. 573-582, 1991.

[20] C. Lundberg, Older Drivers with Cognitive Impairments: Issues of Detection and Assessment, Karolinska Institutet, Stockholm, Sweden, 2003.

[21] N. Stamatiadis and J. A. Deacon, "Trends in highway safety: effects of an aging population on accident propensity," Accident Analysis \& Prevention, vol. 27, no. 4, pp. 443-459, 1995.

[22] W. H. Brouwer and R. W. H. M. Ponds, "Driving competence in older persons," Disability and Rehabilitation, vol. 16, no. 3, pp. 149-161, 1994.

[23] G. E. Stelmach and A. Nahom, "Cognitive-motor abilities of the elderly driver," Human Factors, vol. 34, no. 1, pp. 53-65, 1992.

[24] O. Tsimhoni and P. A. Green, "Visual demand of driving curves as determined by visual occlusion," in Vision in Vehicles VIII, A. G. Gale, I. D. Brown, C. M. Haslegrave, and S. P. Taylor, Eds., Elsevier Science, Amsterdam, The Netherlands, 1999.

[25] F. Schieber, B. Schlorholtz, and R. McCall, "Visual requirements of vehicular guidance," in Human Factors of Visual and Cognitive Performance in Driving, C. Castro, Ed., pp. 31-50, CRC Press, Boca Raton, Fla, USA, 2009.

[26] J. Rogé, T. Pébayle, E. Lambilliotte, F. Spitzenstetter, D. Giselbrecht, and A. Muzet, "Influence of age, speed and duration of monotonous driving task in traffic on the driver's useful visual field," Vision Research, vol. 44, no. 23, pp. 27372744, 2004.

[27] K. K. Ball, D. L. Roenker, V. G. Wadley et al., "Can highrisk older drivers be identified through performance-based measures in a Department of Motor Vehicles Setting?" Journal of the American Geriatrics Society, vol. 54, no. 1, pp. 77-84, 2006.

[28] C. Owsley, K. Ball, G. McGwin et al., "Visual processing impairment and risk of motor vehicle crash among older adults," Journal of the American Medical Association, vol. 279, no. 14, pp. 1083-1088, 1998.

[29] D. L. Roenker, G. M. Cissell, K. K. Ball, V. G. Wadley, and J. D. Edwards, "Speed-of-processing and driving simulator training result in improved driving performance," Human Factors, vol. 45, no. 2, pp. 218-233, 2003.

[30] J. Adrian, "Executive functions contribution to older drivers performance," in Proceedings of 1st International Driver Distraction \& Inattention Conference, Gothenburg, Sweden, September 2009.

[31] M. A. Reger, R. K. Welsh, G. S. Watson, B. Cholerton, L. D. Baker, and S. Craft, "The relationship between neuropsychological functioning and driving ability in dementia: a metaanalysis," Neuropsychology, vol. 18, no. 1, pp. 85-93, 2004.

[32] F. K. Withaar, W. H. Brouwer, and A. H. Van Zomeren, "Fitness to drive in older drivers with cognitive impairment," 
Journal of the International Neuropsychological Society, vol. 6, no. 4, pp. 480-490, 2000.

[33] F. J. Molnar, A. Patel, S. C. Marshall, M. Man-Son-Hing, and K. G. Wilson, "Clinical utility of office-based cognitive predictors of fitness to drive in persons with dementia: a systematic review," Journal of the American Geriatrics Society, vol. 54, no. 12, pp. 1809-1824, 2006.

[34] D. F. Hultsch, E. Strauss, M. A. Hunter, and W. S. MacDonald, "Intraindividual variability, cognition and aging," in The Handbook of Aging and Cognition, F. I. M. Craik and T. A. Salthouse, Eds., pp. 491-556, Psychology Press, New York, NY, USA, 3rd edition, 2008.

[35] S. W. S. MacDonald, L. Nyberg, and L. Bäckman, "Intraindividual variability in behavior: links to brain structure, neurotransmission and neuronal activity," Trends in Neurosciences, vol. 29, no. 8, pp. 474-480, 2006.

[36] D. Bunce, S. W. S. MacDonald, and D. F. Hultsch, "Inconsistency in serial choice decision and motor reaction times dissociate in younger and older adults," Brain and Cognition, vol. 56, no. 3, pp. 320-327, 2004.

[37] D. F. Hultsch, S. W. S. MacDonald, and R. A. Dixon, "Variability in reaction time performance of younger and older adults," The Journals of Gerontology. Series B, vol. 57, no. 2, pp. P101-P115, 2002.

[38] D. F. Hultsch, S. W. S. MacDonald, M. A. Hunter, J. LevyBencheton, and E. Strauss, "Intraindividual variability in cognitive performance in older adults: comparison of adults with mild dementia, adults with arthritis, and healthy adults," Neuropsychology, vol. 14, no. 4, pp. 588-598, 2000.

[39] D. Bunce, R. Handley, and S. O. Gaines, "Depression, anxiety, and within-person variability in adults aged 18 to 85 years," Psychology and Aging, vol. 23, no. 4, pp. 848-858, 2008.

[40] D. Bunce, M. Tzur, A. Ramchurn, F. Gain, and F. W. Bond, "Mental health and cognitive function in adults aged 18 to 92 years," The Journals of Gerontology. Series B, vol. 63, no. 2, pp. P67-P74, 2008.

[41] D. Bunce, K. J. Anstey, H. Christensen, K. Dear, W. Wen, and P. Sachdev, "White matter hyperintensities and within-person variability in community-dwelling adults aged 60-64 years," Neuropsychologia, vol. 45, no. 9, pp. 2009-2015, 2007.

[42] D. Bunce, K. J. Anstey, N. Cherbuin et al., "Cognitive deficits predict frontal and temporal lobe white matter lesions in middle-aged adults living in the community," PLoS One, vol. 5, no. 10, Article ID e13567, 2010.

[43] J. R. Bloomfield and S. A. Carroll, "New measures of driving performance," in Contemporary Ergonomics, S. A. Robertson, Ed., pp. 335-340, Taylor \& Francis, London, UK, 1996.

[44] M. S. Young and N. A. Stanton, "Malleable attentional resources theory: a new explanation for the effects of mental underload on performance," Human Factors, vol. 44, no. 3, pp. 365-375, 2002.

[45] M. S. Young and N. A. Stanton, "Taking the load off: investigations of how adaptive cruise control affects mental workload," Ergonomics, vol. 47, no. 9, pp. 1014-1035, 2004.

[46] M. S. Young and N. A. Stanton, "What's skill got to do with it? Vehicle automation and driver mental workload," Ergonomics, vol. 50, no. 8, pp. 1324-1339, 2007.

[47] M. S. Young, S. A. Birrell, and N. A. Stanton, "Safe driving in a green world: A review of driver performance benchmarks and technologies to support 'smart' driving," Applied Ergonomics, vol. 42, no. 4, pp. 533-539, 2011.

[48] R. Harvey, D. Fraser, D. Bonner, A. Warnes, E. Warrington, and M. Rossor, "Dementia and driving: results of a semi-realistic simulator study," International Journal of Geriatric Psychiatry, vol. 10, no. 10, pp. 859-864, 1995.

[49] L. Nilsson, "Safety effects of adaptive cruise control in critical traffic situations," in Proceedings of the 2nd World Congress on Intelligent Transport Systems, vol. 3, pp. 1254-1259, Vehicle, Road and Traffic Intelligence Society, Tokyo, Japan, 1995.

[50] N. A. Stanton and P. Marsden, "From fly-by-wire to driveby-wire: safety implications of automation in vehicles," Safety Science, vol. 24, no. 1, pp. 35-49, 1996.

[51] N. A. Stanton and M. S. Young, "Vehicle automation and driving performance," Ergonomics, vol. 41, no. 7, pp. 10141028, 1998.

[52] P. F. Waller, "Accidents: traffic," in Encyclopedia of Gerontology: Age, Aging, and the Aged, J. E. Birren, Ed., vol. 1, pp. 19-25, Academic Press, San Diego, Calif, USA, 1996.

[53] P. R. Oxley and C. G. B. Mitchell, "Final report on elderly and disabled drivers information telematics (Project EDDIT)," Commission of the European Communities DG XIII, R \& D Programme Telematics Systems in the Area of Transport (DRIVE II), Brussels, Belgium, 1995.

[54] T. Horberry, J. Anderson, M. A. Regan, T. J. Triggs, and J. Brown, "Driver distraction: the effects of concurrent invehicle tasks, road environment complexity and age on driving performance," Accident Analysis \& Prevention, vol. 38, no. 1, pp. 185-191, 2006.

[55] C. Spence and C. Ho, "Crossmodal information processing in driving," in Human Factors of Visual and Cognitive Performance in Driving, C. Castro, Ed., pp. 187-200, CRC Press, Boca Raton, Fla, USA, 2009.

[56] D. A. Fraser, R. E. Hawken, and A. M. Warnes, "Effects of extra signals on drivers' distance keeping-a simulation study," IEEE Transactions on Vehicular Technology, vol. 43, no. 4, pp. 1118-1124, 1994.

[57] S. Keith, M. Bradley, J. Wilson, and G. Whitney, "The development of a participatory research methodology with older drivers," in Proceedings of the TRANSED Conference, Montreal, Canada, June 2007. 


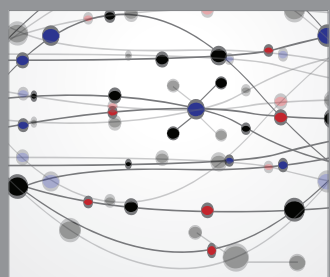

The Scientific World Journal
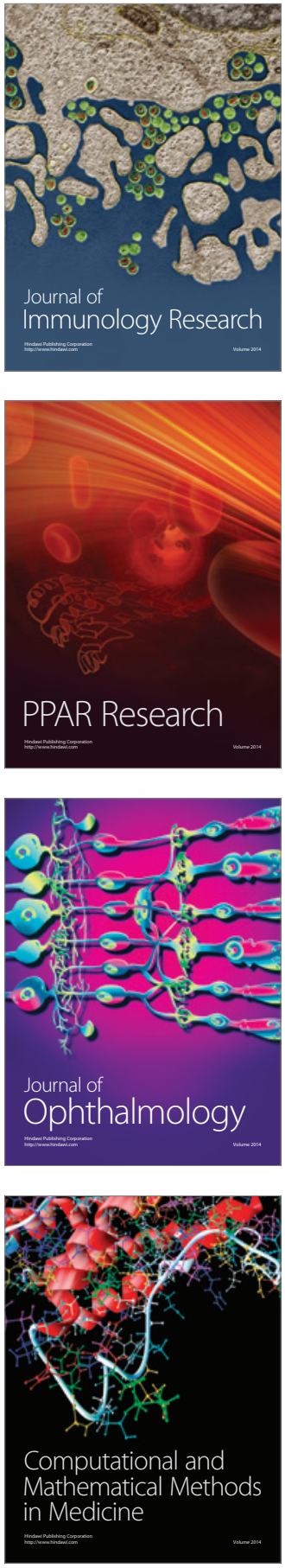

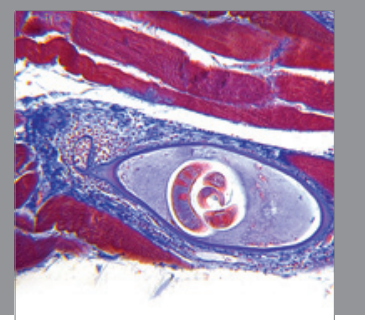

Gastroenterology

Research and Practice
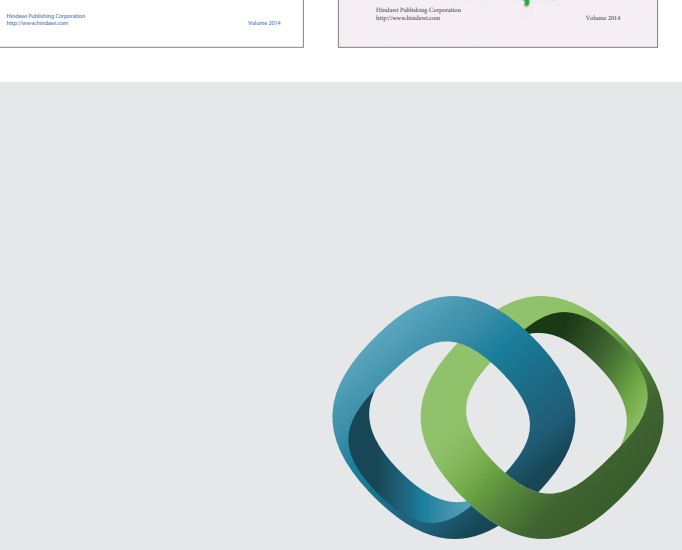

\section{Hindawi}

Submit your manuscripts at

http://www.hindawi.com
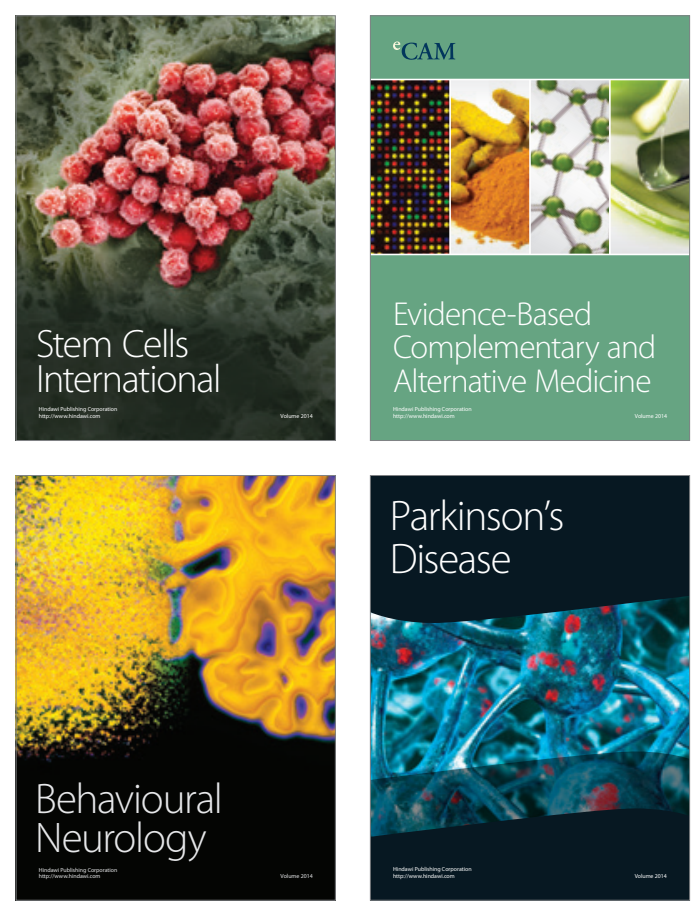

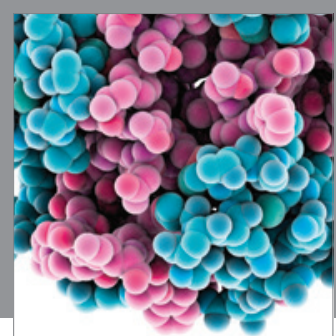

Journal of
Diabetes Research

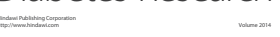

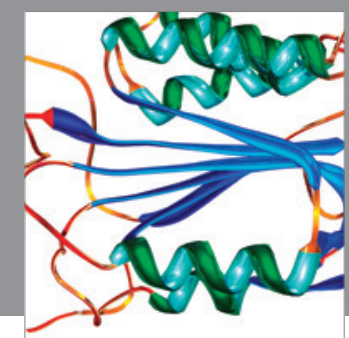

Disease Markers
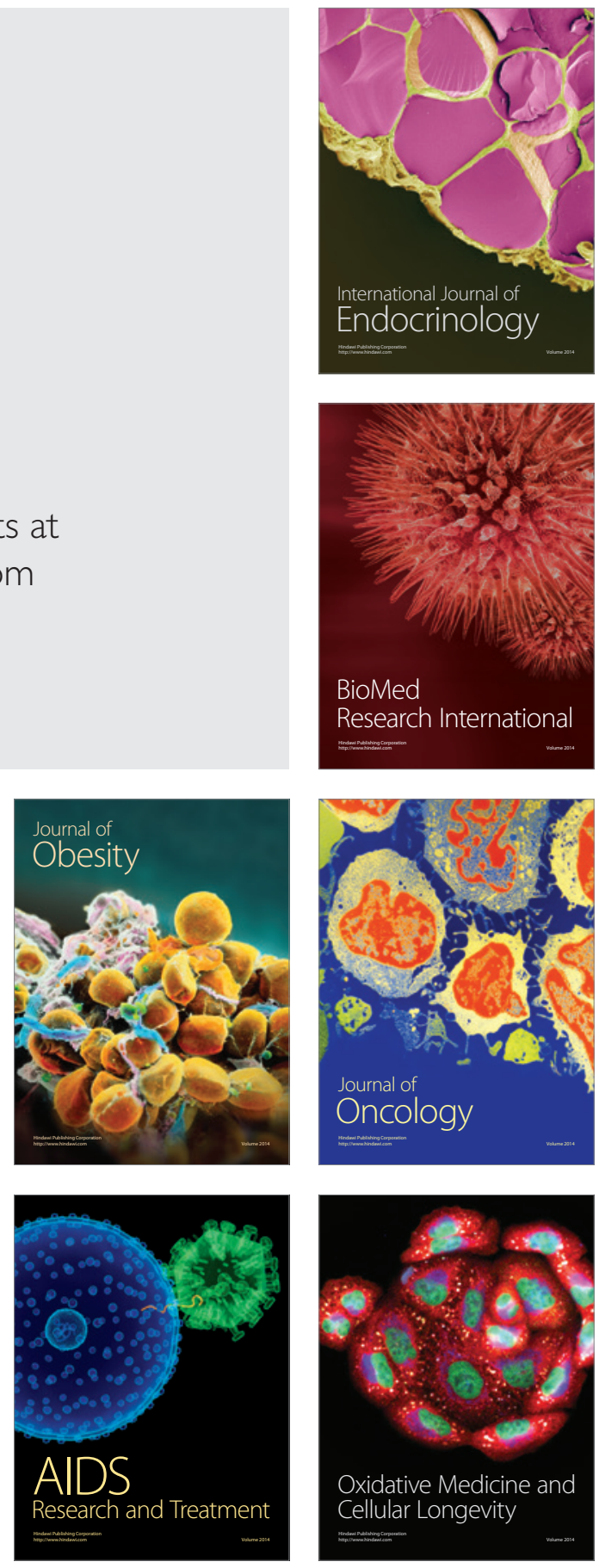